\title{
WELL, WELL, WELL: VARIATION IN DRESS VOWEL REALISATIONS BEFORE LATERAL/L/ IN AUSTRALIAN ENGLISH
}

\author{
Ounu Zakiy Sukaton ${ }^{1}$ \\ ${ }^{1}$ English Letters, Faculty of Languages and Arts, Universitas Ma Chung
}

\begin{tabular}{l}
\hline ARTICLE INFO \\
\hline Received: 20-07-2020 \\
Accepted: 11-10-2020 \\
Published: 12-10-2020 \\
Volume: 4 \\
Issue: 2 \\
DOI: \\
https://doi.org/10.33019/lire.v \\
3i2.90 \\
\hline KEYWORDS \\
\hline
\end{tabular}

Sound merger,

Sociophonetics, Australian

English, Sociolinguistics.

\section{INTRODUCTION} ABSTRACT

The ongoing el-æl merger in Australian English has been informally recognized by Australians especially those who have experience of contact with Victorians. This study aims to investigate the correlation of speakers' sex and origin with their /el/ production and how speech styles influence their production. Two male speakers of Australian English from Victoria and South Australia were recorded while reading texts, doing interviews, and having casual conversations. The recordings were then transcribed and analyzed by using various software to describe their /el/ productions. The result of this study is both male subjects are able to produce considerable variations in their /el/ productions. The production of the Victorian male speaker confirmed the findings of previous studies while the SA male speaker showed variations of /el/ similar to back vowels. Speech styles do not significantly affect the variations of /el/ production. Conclusion: The ongoing merger of el-æl in Australian English might be spreading from Victoria through diffusion to its neighboring states. However, more studies should be conducted in order to confirm this suspicion. Other suggestions include customized reading passages and better semi-structured interviews

A procedure known as 'merger' is where a phonemic contrast is collapsed because of sound change (Hay, Warren, \& Drager, 2006). Thus, two phonemes which were already distinct in a language variety are being acknowledged as a single phoneme. This occurence is normal and has been widely observed by sociolinguists. One of the instances of a merger is the merger of NEAR (/iə/) and SQUARE (/eə/) in New Zealand English (Gordon \& Maclagan, 2001; Hay et al., 2006). Gordon and Maclagan (2001) did a thorough investigation of Christchurch school students whose age were 14 to 15 since 1983. Their investigation proposed that most students produced clear distinction of NEAR (/iə/) and SQUARE (/eə/) vowels in the recording made in 1983 albeit a few varieties were available and there was no clear tendency of converging toward either vowels. In contrast, they found a practically complete merger toward NEAR (/iə/) in 1998. One thing that Gordon and Maclagan didn't consider is the manner by which the students' creation might be different in reading and casual discussion settings. On the off chance that they had tests from students' creation in casual discussions, they may have the chance to recognize the merger sooner. Hay et al (2006) examined the results of this merger in the context of how people will perceive speech. They gathered 71 subjects from University of Canterbury to do perception related tasks by 
listening to recordings performed by 2 male and 2 female speakers of New Zealand English. The subjects were approached to produce NEAR (/iə/) and SQUARE (/eə/) vowels toward the end of the session. The outcomes indicated mixed responses from the subjects which were affected by factors such as various arrangements of background knowledge that the subjects have, and qualities related with the speakers, for example, gender, age, socio-economic status, and education level. In conclusion, social background of the speakers influenced the subjects' impression of their speech production more than the speech itself.

Another case of merger is observed in Australian English. Loakes, Hajek, and Fletcher (2017) investigated an on-going merger of DRESS and TRAP vowels before lateral /l/ as a provincial complement marker of individuals from Melbourne, Victoria. They introduced an informational collection taken from 3 female speakers from greater Melbourne region. Their vowels production from $/ \mathrm{hVd} /$ condition (ex: had, hid, head) is contrasted with their vowels production from the words 'hell' /hel/ and 'Hal' /hæl/. The outcome indicated that/el/ -/æl/ merger was observed in 2 out of 3 speakers. Nevertheless, there were no clarification regarding why the most youthful speaker (age 25) was capable of producing distinct vowels. Additionally, aside from the members' sex and age, there are no social data with respect to the members (ex: education, socio-economic status). The results of this paper is not in line with what Cox and Palethorpe (2004) found. Cox and Palethorpe (2004)found that individuals who live in the outskirt between New South Wales (NSW) and Victoria produce distinctive vowels in $/ \mathrm{hVd} /$ and $/ \mathrm{hVl} /$ conditions. Their subjects who are from Wangaratta, Victoria produced /el/ -/æl/ interchangably while different subjects from NSW didn't. The various outcomes may be brought about by factors such as origin, education, age, and sex. Cox and Palethorpe (2004) controlled their subjects' origin, education, age, and sex while the subjects in Loakes et al. (2017) were picked "because they represent the variability observable in the community" (p. 41) which is an unclear depiction. Nevertheless, Cox and Palethorpe (2004) didn't suspect that the occurence of/el/ -/æl/ might be observeable in casual discussion setting since they requested that their subjects read from a word list. In addition, the two studies referenced above utilized female speakers only as their subjects which is an expected hole in summing up their discoveries. As indicated by Labov (1972), scientists need to contemplate that individuals may talk distinctively when they are not being watched (ex: casual discussions). Henceforth, I speculate various settings may yield various outcomes.

In regards of the past studies, the production of /el/ ought to be dispersed and overlapped between /e/ and /æ/. Consequently, observing the production of DRESS vowel specifically may give us bits of knowledge of what is really going on in this on-going merger. In the light of the gap in research on the /el/-/æl/ merger, I propose an investigation to respond to the following inquiries: 


\section{What is the impact of speaker's sex and origin in the /el/ production?}

2. Do speech styles influence the variety of /el/ production?

These questions are becoming more and more salient due to the insufficient information given in the previous research discussed above. Consequently, it is imperative to address those questions in order to further forward the research on /el/-/æl/ merger in Asutralian English. The result of this study is likely to be a solid stepping stone to the progress of the investigation of /el//æl/ merger in Australian English.

\section{METHODOLOGY}

In the paper, two recordings of one Victoria male speaker by the pseudonym of Ferb and one South Australia male speaker by the pseudonym of Ham will be used. Both speakers are similar in age and level of education. Prior to moving to Canberra for education, they both spent much of their time growing up in their respective hometowns. Ham, however, speaks a second language and he has lived in China for 3 months while Ferb is a monolingual in Australian English. The recordings were done in a secluded space to eliminate noise. ZOOM H5 recorder and head mounted microphone were utilised in all of the recording processes. Three kinds of recording were done by all of the participants. First, three passages which are the North Wind and the Sun, the Grandfather, and the Rainbow passage were read by the participants and recorded. Second, the participants were asked to do a recorded interview for 20 to 30 minutes. Finally, the participants documented themselves having 20 to 30 minutes discussion with their friends or family members. The aim of providing various styles of recording is to elicit speech output from the participants in reading, formal, and casual context. The recordings will subsequently be anonymised using Audacity (AudacityTeam, 2017) and ELAN (Lausberg \& Sloetjes, 2009) was used to transcribe the recordings. ELAN orthographic transcription must then be forwarded to PRAAT (Boersma \& Weenink, 2018). In this paper, all measurement of the formants of vowels will be done in PRAAT.

The next step is to calculate the average value of the different vowels that each speaker generates. The first and second formant of Australian English vowels in Cox and Palethorpe's (2007) illustration will be counted four times in each recording for a total of 12 tokens per vowel (see Di Paolo, Yaeger-Dror, \& Wassink, 2011 for reference number of tokens). As per Di Paolo et al. (2011), the conditions from which the measurements of vowels are taken should be in a neutral phonetic consonant setting. If such environment is not provided in the data, however, some convenient samples will be selected instead and some notes followed. In short, two vowel plots (one for each speaker) will be presented in the study containing the mean value of each vowel. 
Afterwards, Lobanov (1971) normalisation method will be applied to all of the vowel plots. This approach is chosen because variations in formant values caused by physiological factors can be factored out. Additionally, when all the vowels from the speakers' inventory are included, it works optimally. Finally, according to Adank, Smits and Van Hout (2004), the Lobanov normalisation method performed the best of all techniques tested in a discriminatory analysis of normalised Dutch vowels which is a close relative of the English language. 'Well' occurrences were then coded and the vowel formant values in the word 'well' were calculated. In addition, 'well' vowel measurements will be plotted against mean values of the vowel plot of each speaker to evaluate any variations that occur.

In short, the main research methodology employed in this study is phonetic acoustic analysis combined with descriptive qualitative. After the result was gained, further description of data as well as critical discussion were conducted. The methodology was heavily inspired by the previous study regarding (Cox \& Palethorpe, 2004; Loakes et al., 2017). However, added procedures were applied to address the gaps mentioned in the research questions.

\section{RESULTS}

Ferb's and Ham's vowels have different concentration points in their vowel plots when the plots are normalised (figure 1 and figure 2). Compared to Ham's, Ferb's vowels are concentrated more to the front. On the other hand, Ham tends to produce vowels to the back of his tongue. If we have a look at figure 1 and 2, we can see Ferb's and Ham's variability in producing vowels.
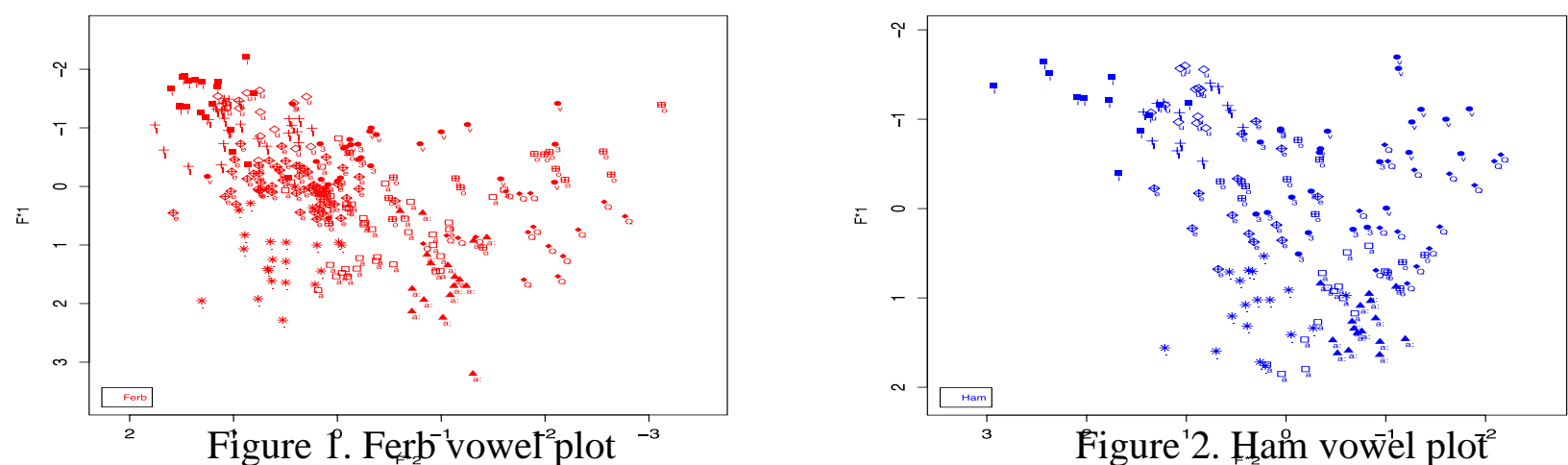

Ferb and Ham have managed to produce distinct/e/ and /æ/ in most environments throughout the recordings. We can see it from their/e/ and /æ/ measures (see table 1). Ferb's/e/ and/æ/ output 
is more stable than Ham's is. We can see from table 1 that Ham has more variations in his / her / its performance (represented by the standard $\mathrm{f} 1$ and $\mathrm{f} 2$ deviation values). In fact, the value of Ferb's $\mathrm{f} 1 \mathrm{in} / \mathrm{e} /$ is lower than that of Ham which means that Ferb's /e/ is very high relative to Ham's. All the vowel measurements were performed at 50 percent of the length of the vowels since this paper is only interested in monophthong (see Di Paolo et al., 2011 for reference of the vowel measurement).

Table 1. Ferb and Ham /e/ and /æ/measurements

\begin{tabular}{lllllll} 
Speaker & Vowel & Mean F1 & Mean F2 & n & SD F1 & SD F2 \\
\hline Ferb & $\mathfrak{x}$ & 649 & 1749 & 12 & 64 & 50 \\
\hline Ferb & e & 492 & 1708 & 12 & 30 & 67 \\
\hline Ham & $\mathfrak{x}$ & 760 & 1661 & 12 & 60 & 67 \\
\hline Ham & $\mathrm{e}$ & 529 & 1716 & 12 & 91 & 125
\end{tabular}

Yet, their /e/ before lateral/1/ productions have a lot of variations. In table 2, we can see how the supposedly /e / in /wel/ varied in values of f1 and f2. The Ferb's /e/ f1 values range from 515 $\mathrm{Hz}$ to $746 \mathrm{~Hz}$ while the f2 values range from $905 \mathrm{~Hz}$ to $2046 \mathrm{~Hz}$. In contrast, Ham's /e/ f1 values have a range of $476 \mathrm{~Hz}$ to $831 \mathrm{~Hz}$ while the f2 values are between $824 \mathrm{~Hz}$ and $1526 \mathrm{~Hz}$. The highest occurrence of 'well' is found within their self-recordings while only one token is found from the reading passage.

Table 2. DRESS Vowel realisations in /wVl/ environment

\begin{tabular}{|c|c|c|c|c|}
\hline Speaker & Word & Style & F1 & F2 \\
\hline Ferb & well & reading & 603 & 1303 \\
\hline Ferb & well & interview & 515 & 1000 \\
\hline Ferb & well & interview & 683 & 1745 \\
\hline Ferb & well & interview & 563 & 2046 \\
\hline Ferb & well & self-recording & 746 & 1956 \\
\hline Ferb & well & self-recording & 742 & 1778 \\
\hline Ferb & well & self-recording & 518 & 995 \\
\hline Ferb & well & self-recording & 440 & 905 \\
\hline
\end{tabular}




\begin{tabular}{|c|c|c|c|c|}
\hline Ham & well & reading & 712 & 1526 \\
\hline Ham & well & interview & 782 & 1442 \\
\hline Ham & well & interview & 706 & 1159 \\
\hline Ham & well & interview & 476 & 824 \\
\hline Ham & well & interview & 802 & 1128 \\
\hline Ham & well & self-recording & 831 & 1215 \\
\hline Ham & well & self-recording & 492 & 1097 \\
\hline Ham & well & self-recording & 678 & 1196 \\
\hline Ham & well & self-recording & 631 & 1252 \\
\hline Ham & well & self-recording & 722 & 1330 \\
\hline
\end{tabular}

The results of this study is more or less in line with what Cox and Palethorpe (2004) as well as Loakes et al. (2017) found in their study. Ferb, who is from Melbourne greater area, has a tendency to produce a variety of /el/ with similar quality of /æl/ as illustrated in Figure 1 . What was different is that Ferb also produced /el/ with the quality of back vowels during self-recording as illustrated in Table 2. This result was not found in those two previous studies. Moreover, the /el/ production with the quality of back vowels is dominant in Ham's data. According to these specific results, further discussion will be provided in the next section.

\section{DISCUSSION}

It's clear that Ferb and Ham have different space arrangement for their vowels. When we go back to table 1, we 'd assume that, due to the standard deviation values of his $\mathrm{f} 1$ and $\mathrm{f} 2$, Ham would most likely have more differences in his DRESS vowel realisations. However, we can observe $\mathrm{in} / \mathrm{wVl} /$ environment that Ferb has more variations in the realisation of his DRESS vowel, particularly in the range of his $\mathrm{f} 2$ (see figure 3). Figure 3 indicates Ferb develops four DRESS vowels with qualities of $\mathrm{f} 1$ and $\mathrm{f} 2$ close to front vowels. That finding is in line with what was found in the analysis of Cox and Palethorpe (2004) and Loakes et al. (2017). Their Victorians subjects produced similar vowels as in figure 3 to what Ferb displays. What the previous study did not reveal, however, is the fact that Ferb also produces three DRESS vowels with similar qualities of $\mathrm{f} 1$ and $\mathrm{f} 2$ to back vowels and 1 DRESS vowel with similar qualities of $\mathrm{f} 1$ and $\mathrm{f} 2$ to central vowels. The latter findings are surprising since, so far, no research has found that /el/ realisations can produce vowels with back vowel formant qualities. 


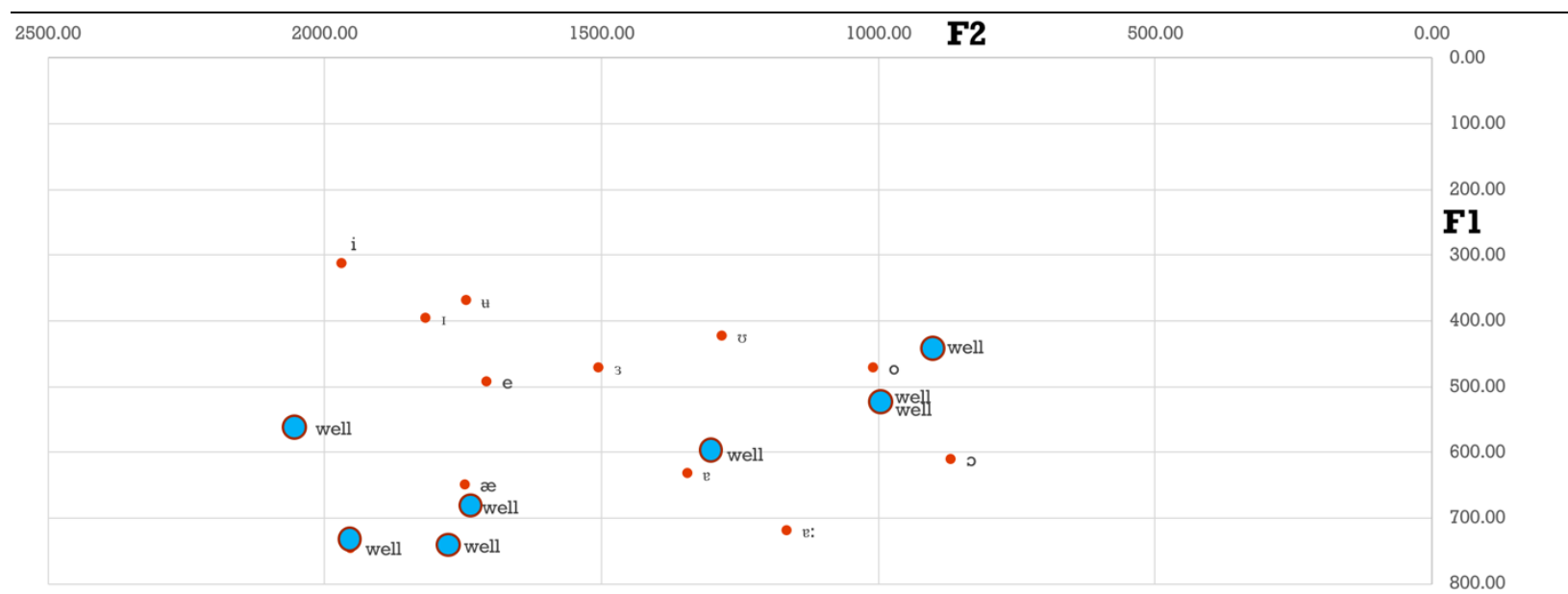

Figure 3. Ferb DRESS vowel realisations in /wVl/ environment

Ham, who came from Adelaide, SA, also surprisingly produces a variety of DRESS vowels in the environment of /wVl/. In previous studies on /el/-/æl/ merger, this result was never observed. Moreover, most of his DRESS vowel realisations have the central and back vowel f1 and f2 consistency. No tokens were found in his recordings to be of the $\mathrm{f} 1$ and $\mathrm{f} 2$ standard of front vowels. While his mean DRESS vowel value has dynamic standard deviation values for f1 (SD = 91) and f2 ( $\mathrm{SD}=125)$, his DRESS vowel realisations in $/ \mathrm{wVl} /$ sense seems to be far beyond what he usually produces.

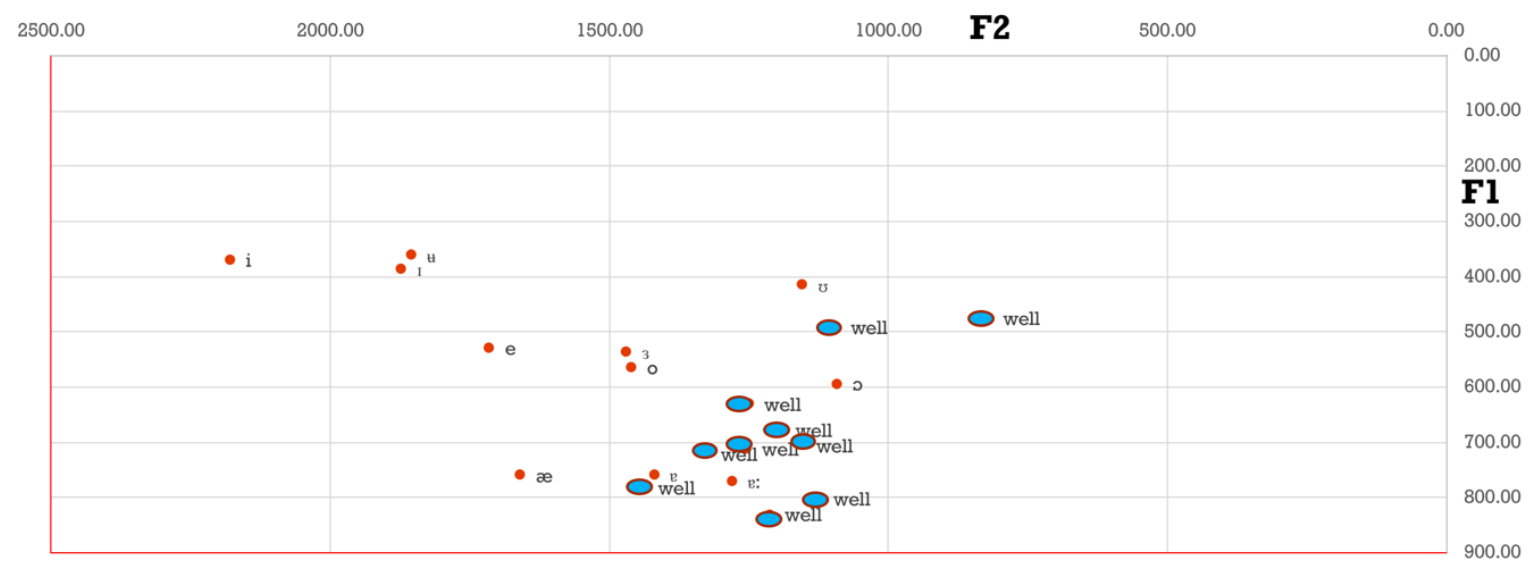

Figure 4. Ham DRESS vowel realisations in /wVl/ environment 
When we compare DRESS vowel realisations of Ferb and Ham in/wVl/ setting, we can see that their realisations are different in concentration. The realisations of Ferb are spread widely, while Ham's realisations are more concentrated to the centre of his vowel space. Those patterns relate, in a way, to their normalised vowel plots. Compared to Ferb's vowels, Ham's vowels tend to be more concentrated toward the back. However, in the case of Ham, there are no DRESS vowel realisations in $/ \mathrm{wVl} /$ setting that are even similar to the target quality of his usual production of DRESS vowel. In this regard, we could suspect that Ham's second language could play a role in his choice of vowel in $/ \mathrm{w} \mathrm{Vl} /$ environment.

The realisations of DRESS vowel in /wVl/ environment do not seem to be affected by speech style in this study. But for both Ferb and Ham, there's only one token of 'well' in reading context. On the one hand, this particular problem does not seem to influence the assessment of Ham's DRESS vowel realizations in /wVl/ setting since none of his realizations in other environments have similar f1 and f2 consistency to his DRESS vowel. Ferb's 'ok' token in reading, on the other hand, is the only realization of DRESS vowel in $/ \mathrm{wVl} /$ setting that has comparable consistency to its central vowels. Ferb's 'well' token in reading, on the other hand, is the only realization of DRESS vowel in $/ \mathrm{wVl} /$ setting that has comparable consistency to its central vowels. Therefore, to decide the role of speech style in DRESS vowel realisations in $/ \mathrm{wVl} /$ setting, more 'well' tokens in reading activitywould be a great addition.

It is unusual to be able to observe some variations of DRESS vowel realisations in Ham's results, although it is not an uncommon occurrence as well. Labov (2007) proposed that languages could change through transmission and diffusion. Language change through transmission occurred in the same speech culture across different generations. The younger generations adopted what the older generations produced, and further advanced the characteristics that distinguished them from what the older generations produced. By comparison, language change by diffusion is the result of the cultures of speech being in contact. The change is progressing slower in this respect and is less structured than transmission.

Clark and Watson (2016) researched the language shift argument of Labov by studying different realisations of lenited / $\mathrm{t} /$ in Liverpool and its surrounding cities, Skelmersdale and St. Helens. Their study results backed Labov 's claim to language change through transmission and diffusion. The Liverpool variant of $/ \mathrm{t} / \mathrm{are} / \mathrm{t} \theta_{2} \theta_{2} \mathrm{~h} /$ and these variants are largely retained by the town of Skelmersdale. Clark and Watson suspected that it happened because of massive migration of people from Liverpool to Skelmersdale in the 1960s and ongoing contact between two speech communities (p. 59). Most of the younger generations of Skelmersdale demonstrated the use of $/ t \theta_{2} \theta_{2} h /$ in their daily speech rather than their peers in St. Helens. In St. Helens, the use of $/ t_{2} \theta_{2}$ 
$\mathrm{h} /$ variants are slowly being replaced by / $/$ /. / / has been observed longer in Manchester rather than Liverpool (Baranowski \& Turton, 2015). Thus, Clark and Watson (2016) suspected that this feature is more likely to spread via diffusion from Manchester rather than Liverpool (p. 59).

No claim can be made in the case of Ham and Ferb with only the two people's data. Change by diffusion, however, is more likely to occur rather than transmission. Earlier studies (e.g. Cox \& Palethorpe, 2004; Loakes et al., 2017) observed predominantly Victorian-speaker variations in prelateral DRESS vowels. In this case, whether it were to happen through transmission or there were mass migrations from Victoria to South Australia, the particular language shift would have to originate from South Australia. Instead, the more likely scenario is that, given their close proximity, language contacts between Victoria and South Australia are constantly occurring and this feature is being transferred during language contact. The complicated partnership between Victoria, South Australia, and New South Wales may be another explanation for this phenomenon. Victoria and NSW have a long history of unpleasant association, according to Davison, Hirst, and Macintyre (2001). The two states were continually fighting over which state would host Australia's capital city before the Australian government agreed to create Australian Capital Territory (ACT) and named Canberra as Australia's capital city to end the dispute. Through this context, citizens of NSW and Victoria do not maintain each other's speech identity marker (e.g., el-æl merger) to draw a strong line of identity distinction. On the other hand, between the state of Victoria and South Australia, no major relationship issues are identified. The supportive attitude towards the speech of Victoria speakers in residents of South Australia may be a key to al-æl merger through regional diffusion.

\section{CONCLUSION}

This study discusses the probability of differences in the Australian English prelateral DRESS vowel. While this research does not explicitly compare DRESS vowel and TRAP vowel prelaterals, the realizations of DRESS vowel prelaterals in this research might provide further insight into the ongoing merger of el and $æ l$ in Australian English. Variations in DRESS vowel realisations in $/ \mathrm{wVl} /$ context can be found from male subjects that were not previously examined. In addition, variations in DRESS vowel realizations in $/ \mathrm{wVl} /$ environment are surprisingly noticeable from SA's male subject. Although this finding is surprising, this study attempted to clarify how this phenomenon could have occurred in limited detail. Additionally, both subjects produced realisations of the prelateral DRESS vowel with the formant qualities of back vowels. This result indicates that more things are happening in this ongoing merger than simply mergering el-æl. Finally, there would seem to be no important association between the frequency of prelateral 
DRESS vowel differences associated with speech styles. However, there are some other things to consider. First, there are not enough tokens in the data to fully support this claim, particularly in reading background recordings. Second, more tokens will be required to perform a statistical test to determine whether the speech style affects prelateral DRESS vowel variations in Australian English

There are some suggestions for potential studies in Australian English about the ongoing elæl merger. First, tracing how far the phenomenon has spread from its original source would be useful. The fact that SA speaker is demonstrating variations of prelateral DRESS vowel may mean that el-æl merger is not limited to people from the Victoria state. Second, it would also be useful to further explore the connection between speech style and el-æl merger. A personalized reading passage (e.g. a reading passage about 'celery' and 'salary') needs to be made to get the required amount of el or æl tokens. In addition, a better semi-structured interview and self-recording (e.g. talk about 'well,' 'celery,' or 'salary') needs to be done. Furthermore, more tokens can be created by increasing the number of people in future studies. Ultimately, a detailed review is also suggested on why there are certain prelateral DRESS vowel realisations with the formant qualities of back vowels.

\section{ACKNOWLEDGEMENT}

This study would not be possible without the support of Ma Chung university research funding. Therefore, I'd like to thank Ma Chung university and everyone that were involved in this study.

\section{ABOUT THE AUTHOR(S)}

My name is Ounu Zakiy Sukaton and I am currently teaching at Ma Chung university, Malang. I teach linguistics courses in Ma Chung such as Sociolinguistics, Phonetics and Phonology, Psycholinguistics, and other linguistics related courses. My research interest lies in the intersection of language variations and forensic linguistics especially voice comparison. My strength is phonetics-based analysis with computer-assisted tools. 


\section{REFERENCES}

Adank, P., Smits, R., \& Van Hout, R. (2004). A comparison of vowel normalization procedures for language variation research. The Journal of the Acoustical Society of America, 116(5), 3099-3107.

AudacityTeam. (2017). Audacity(R): Free Audio Editor and Recorder [Computer application] (2.2.1). 2.2.1. Retrieved from https://audacityteam.org/

Baranowski, M., \& Turton, D. (2015). Manchester English. In R. Hikcey (Ed.), Researching Northern English (pp. 283-305). Amsterdam: Benjamins.

Boersma, P., \& Weenink, D. (2018). Praat: doing phonetics by computer (6.0.37). 6.0.37. Retrieved from http://www.praat.org/

Clark, L., \& Watson, K. (2016). Phonological leveling, diffusion, and divergence:/t/lenition in Liverpool and its hinterland. Language Variation and Change, 28(1), 31-62.

Cox, F., \& Palethorpe, S. (2004). The border effect: Vowel differences across the NSW-Victorian border. In C. Marovsky (Ed.), Proceedings of the 2003 Conference of the Australian Linguistic Society (pp. 1-27).

Cox, F., \& Palethorpe, S. (2007). Australian English. Journal of the International Phonetic Association, 37(3), 341-350.

Davison, G., Hirst, J., \& Macintyre, S. (2001). The Oxford Companion to Australian History. Oxford University Press.

Di Paolo, M., Yaeger-Dror, M., \& Wassink, A. B. (2011). Analyzing vowels. In M. Di Paolo \& M. Yaeger-Dror (Eds.), Sociophonetics: A student's guide (pp. 87-106). Abingdon, Oxon: Routledge.

Gordon, E., \& Maclagan, M. (2001). "Capturing a Sound Change": A Real Time Study Over 15 Years of the NEAR/SQUARE Diphthong Merger in New Zealand English. Australian Journal of Linguistics, 21(2), 215-238.

Hay, J., Warren, P., \& Drager, K. (2006). Factors influencing speech perception in the context of a merger-in-progress. Journal of Phonetics, 34(4), 458-484.

Labov, W. (1972). Sociolinguistic patterns. Pennsylvania: University of Pennsylvania Press.

Labov, W. (2007). Transmission and diffusion. Language, 81(2), 344-387.

Lausberg, H., \& Sloetjes, H. (2009). Coding gestural behavior with the NEUROGES-ELAN system. Behavior Research Methods, 41(3), 841-849.

Loakes, D., Hajek, J., \& Fletcher, J. (2017). Can you t [æ] 11 I'm from M [æ] lbourne? English World-Wide, 38(1), 29-49. 
Lire Journal (Journal of Linguistics and Literature)

https://lirejournal.ubb.ac.id/index.php/LRJ/index

Cinta

P-ISSN: 2598-1803 E-ISSN: 2581-2130

Volume 4 Number 2 October 2020

Lobanov, B. M. (1971). Classification of Russian vowels spoken by different speakers. The Journal of the Acoustical Society of America, 49(2B), 606-608.

\section{(c) $(9)$ (9)}

This work is licensed under Creative Commons Attribution-ShareAlike 4.0 Internasional.

Copyright @ 2020, Ounu Zakiy Sukaton 